\title{
Comparison and significance of auroral studies during the Swedish and Russian bilateral expedition to Spitsbergen in 1899-1900
}

\author{
S. Chernouss ${ }^{1}$ and I. Sandahl ${ }^{2}$ \\ ${ }^{1}$ Polar Geophysical Institute of the Kola Science Centre RAS, Apatity, Murmansk region, 184209 Russia \\ ${ }^{2}$ Swedish Institute of Space Physics, Kiruna, Sweden
}

Received: 7 February 2007 - Revised: 3 August 2007 - Accepted: 11 August 2007 - Published: 28 May 2008

\begin{abstract}
Results of measurements and visual observations of aurora at Spitsbergen, carried out by the joint SwedishRussian expedition during 1899-1900, are described. Auroral observations took place during the great bilateral Arc-ofMeridian expedition, which was patronized by the Swedish Royal Family and the Russian Imperial Family. The RussianSwedish Arc-of-Meridian measurements were closely coordinated but auroral measurements from the two sites in the Spitsbergen Archipelago were almost independent of each other. The basic auroral data for our presentation are reports of the Russian astronomer Josef Sykora and the Swedish geophysicist Jonas Westman. Both scientists used similar types of photo cameras and spectrographs, which were the best at that time and were made in Potsdam by Toepfer. Detailed descriptions of the optical devices and the system of spectral calibration are presented. A Toepfer spectrograph, possibly the one used by Westman, is still kept at IRF in Kiruna. We present a comparative analysis of auroral data from the Russian and Swedish stations on three themes: visual observations of aurora, describing features of auroral forms and giving us statistical data on aurora occurrence and the heights of aurora, photos of aurora, and auroral spectra. It is shown that the observations contain enough data to construct an auroral oval and to determine the heights of aurora. The expedition obtained the first photographic observations of the aurora in the Arctic. The auroral spectra demonstrate a high spectral resolution and show not only the main auroral emissions in the blue-green spectral range but also some weak emissions in the violet and ultraviolet region. All data are interpreted from a modern point of view. The Russian-Swedish 18991900 expedition carried out the first complex auroral investigations in the Arctic using optical instruments and presented well documented data and new results.
\end{abstract}

Keywords. History of geophysics (Instruments and techniques) - Ionosphere (Auroral ionosphere)

Correspondence to: S. Chernouss

(chernouss@pgi.kolasc.net.ru)

\section{Introduction}

This paper will review the auroral observations carried out in 1899-1900 at Spitsbergen in extensive fieldwork during the Swedish-Russian Arc-of Meridian expedition (CarlheimGyllensköld, 1900; Wråkberg, 2002) and presents results of recent reanalysis of the data. The main reason for writing this paper was that the Russian and Swedish auroral measurements were never discussed together as a joint work. A reanalysis of Russian data has been reported by Chernouss et al. (2005).

The Spitsbergen Archipelago is situated at extremely high geographic and geomagnetic latitudes (Fig. 1), where in the daytime the geomagnetic field allows for direct entry of solar wind particles down to the upper atmosphere. This "open window in the magnetosphere", the cleft or cusp, has some ionospheric and ground-based signatures as, for example, special types of dayside and polar cap aurora and variations of the geomagnetic field (Sandholt et al., 2002; Yevlashin, 1968; Eather, 1980; Deehr and Egeland, 1972). Spitsbergen is an unusual place, where it is possible to see all parts of the auroral oval and it is particularly good for observations of the auroral oval during low geomagnetic activity. In December and January aurora can be observed around the clock. These features have drawn the attention of many research groups in the world, who are operating several observatories there. Modern facilities were first built during IGY (1957-1958) in the Russian station Piramida, then in the Norwegian stations Longyearbyen and Ny Ålesund. After that, long-term observations started at the Russian observatory in Barentsburg and the Polish station at Hornsund. This research will be more active during the International Polar Year 2007-2009. The first long-term observations of aurora in Spitsbergen were carried out already during the first International Polar Year $1882-1883$ by the Swedish expedition at Cape Thordsen (Carlheim-Gyllensköld, 1886; Alfvén, 1967), but auroral photography was then still immature and was not used. Our study is based on reports by the Russian and Swedish auroral teams (Sykora, 1901a,b, 1903; Westman, 1904), their

Published by Copernicus Publications on behalf of the European Geosciences Union. 


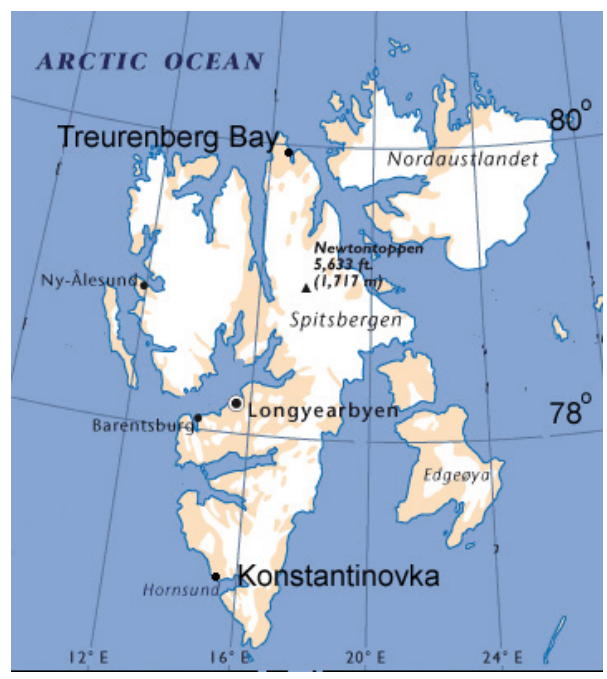

Fig. 1. Map of Spitsbergen showing the positions of the Russian station Konstantinovka and the Swedish station at Treurenberg Bay.

published and hitherto unpublished data, letters and diaries of observations from the national archives and other sources.

\section{The Russian-Swedish expedition to Spitsbergen in 1898-1902}

The main aim of the Russian-Swedish expedition was to measure very precisely the length along the surface of the Earth of one degree of latitude, to compare with such a length measured closer to the equator (Carlheim-Gyllensköld, 1900; Wråkberg, 2002). This was to be used to establish the exact shape of the Earth, in particular its flattening towards the pole. The Russian astronomical observatory in Pulkovo had played a crucial role in the program of the big European triangulation in the 19th century. A couple of Swedish astronomers had been working there, among them Oskar Baklund, who facilitated the setting up of a cooperation between the Pulkovo Observatory of the Russian Imperial Academy of Sciences and the Royal Swedish Academy of Sciences. After official scientific approval this bilateral project was taken up at the highest national level. Grand Duke Kniaz Konstantin, who was president of the Russian Imperial Academy of Sciences and cousin of the Russian tsar, was head of the project from the Russian side. Crown Prince Gustav of Sweden, who later became King Gustav $\mathrm{V}$, was head of the project from the Swedish side. Academic leaders of the two countries defined the scientific programme of the expedition and one of their decisions was to widen the research objectives and to include not only geodetic measurements but also meteorological, geological, geomagnetic and auroral studies. Hence, investigations of aurora became a substantial part of the scientific programme of the expedi-


Fig. 2. Above:The Russian scientific team and crew members of the ship Bakan on board the ship. Below: The Swedish expedition team at Treurenberg Bay on occasion of the roof laying party.

tion. This Spitsbergen expedition was the first bilateral and the most closely coordinated scientific work ever done in the Arctic until then (Wråkberg, 2002), matched only in some respects by the international coordination in meteorology and geomagnetic science done in 1882-1883 during the first International Polar Year.

Both the Swedish and the Russian expedition teams (Fig. 2) arrived at Spitsbergen in the summer of 1899. All necessary building materials and equipment were brought by ships and the stations were set up at Treurenberg Bay (Geographic: $79.9^{\circ} \mathrm{N}, 16.8^{\circ} \mathrm{E}$; Corrected geomagnetic: $75.3^{\circ} \mathrm{N}$, $122.5^{\circ} \mathrm{E}$ ) and Goose Bay at Hornsund (Geographic: $76.8^{\circ} \mathrm{N}$, $15.4^{\circ} \mathrm{E}$; Corrected geomagnetic: $72.7^{\circ} \mathrm{N}, 114.8^{\circ} \mathrm{E}$ ). The Russian station was named "Konstantinovka", in honor of the Grand Duke Kniaz Konstantin. Both stations consisted of several buildings for experimental work, living and other purposes (Fig. 3).

The auroral observations of the Swedish team were directed and to a large extent carried out by Jonas Westman (Fig. 4a) and of the Russian team by Josef Sykora (Fig. 4b). The main aims were the investigation of images and spectra 


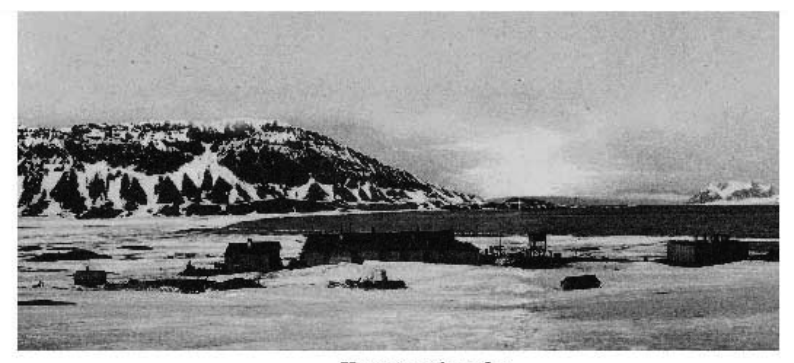

Konstantinovka

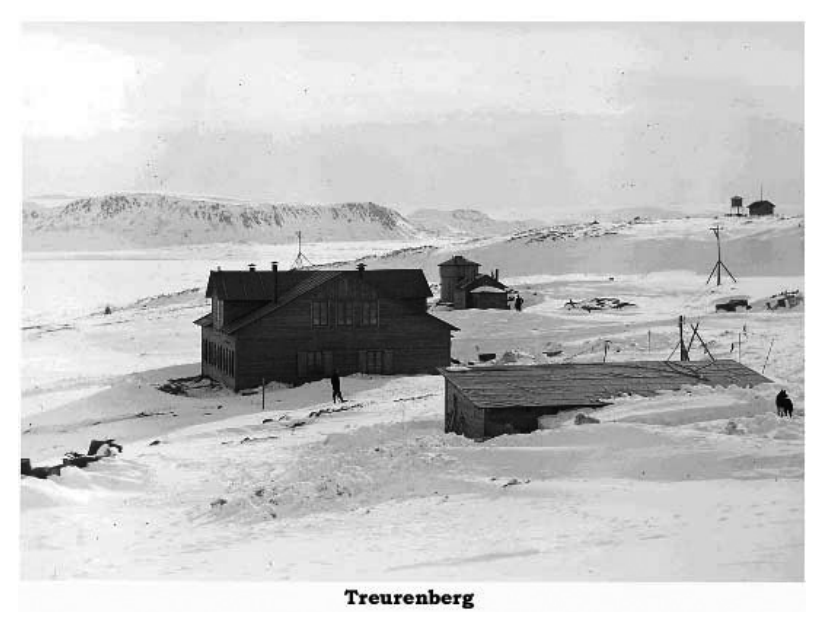

Fig. 3. Above: The Russian expedition base Konstantinovka in Hornsund, Goose Bay. Below: The Swedish expedition base at Treurenberg Bay.

of aurora, their temporal and spatial variations, and the mapping of aurora.

\section{Materials and methods}

\subsection{Visual observations}

Visual observations and measurements of auroral positions by comparison with the star background and by theodolites constitute a big part of the experimental data obtained at both observatories. Descriptions of those data and tables are presented in the reports by Sykora and Westman (Sykora, 1901a,b; Westman, 1904) (Figs. 5a and 5b). According to the observation schedule of the expedition, aurora was to be noted daily at 07:00, 09:00, 11:00, 13:00, 16:00, 18:00, 20:00, 21:00, and 22:00 UT. Every five days observations were to be made at both stations every 15 min between 20:00 and 22:00 UT. In practice, the planned scheme for simultaneous observations at both stations was not strictly adhered to.

Sykora observed about 1100 auroral events from September 1899 to February 1900 and Westman about 1400 events during the same period. Aurora was reported during 132

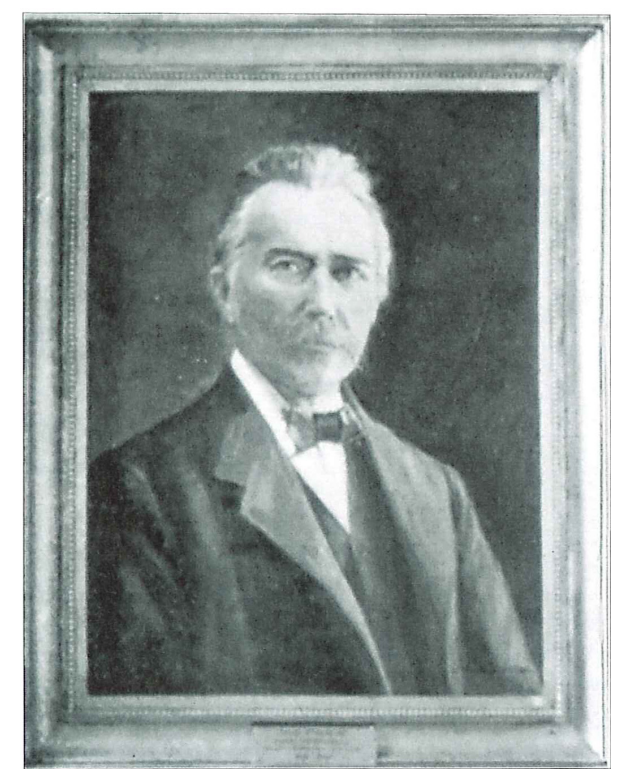

Fig. 4a. Jonas Westman was born 1867 in Nora, a rural parish located on the Baltic coast of Sweden between Sundsvall and Umeå. He must certainly have been able to see aurora on many occasions during his early years. His family was obviously interested in education and his grandfather had served on the local school board. Westman received his doctor's degree in Uppsala in 1897 and then served there as docent of meteorology until 1904. At the same time he also worked for "Meteorologiska centralanstalten", a predecessor of the present Swedish Meteorological and Hydrological Institute and at the Meteorological observatory in Uppsala. Before the Svalbard expedition Westman had proven his ability in the field during studies of glaciers in the Sulitelma region in Swedish Lapland in 1897-1898. In 1904 he moved to a position as lector of mathematics and physics at the upper secondary school in Nyköping about $80 \mathrm{~km}$ southwest of Stockholm and from 1914 until his death in 1922 he served as headmaster there. He wrote quite a few scientific papers and reports and continued to carry out meteorological and hydrological investigations during his time as lector and headmaster (Nordisk Familjebok, 1921; Nordlander, 2006).

days at Treurenberg Bay and 94 days at Konstantinovka. The Swedish observers identified the following formalized parameters of the aurora in UT: occurrence of aurora, auroral forms and their structure (arcs, rayed arcs, coronas, isolated rays, bands, vortices, background luminosity), azimuth (for two ends of continuous forms) and elevation angles (for lower border at the eastern and western ends of auroral forms and for the aurora situated on a straight line between Konstantinovka and Treurenberg Bay), intensity of aurora in relative units (scale from 1 to 6), angular velocity of auroral forms, aurora colors. The temporal resolution of their observations varied from several minutes to several hours, depending on auroral activity. The angular measurements were carried out by theodolites, sometimes the position of auroral forms relative to observed stars was pointed out. 


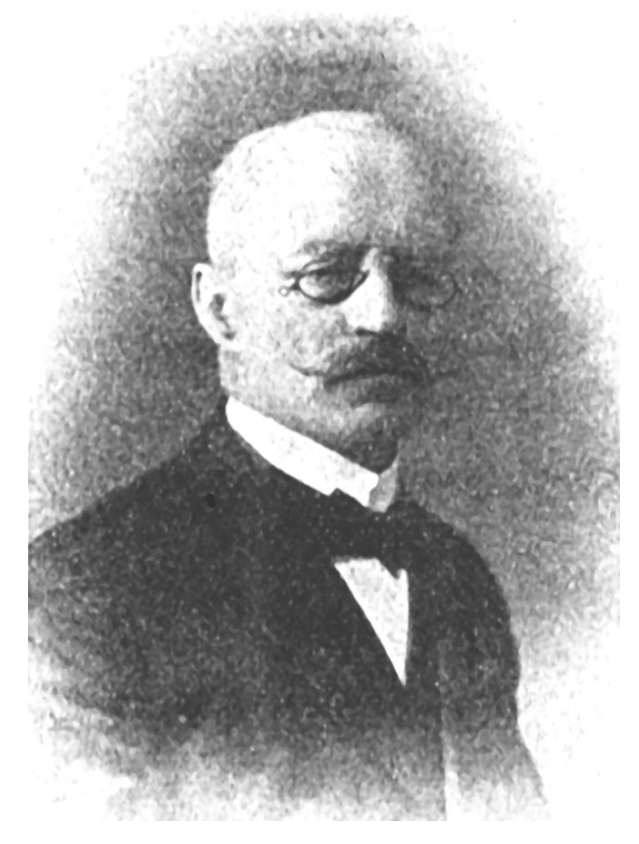

Fig. 4b. Josef Sykora was born in Kharkov in Ukraine in 1874, a son of Czech immigrants. He began his scientific career in astronomy at the Kharkov University. His first scientific works, concerning observations of the Solar Eclipse in northern Finland and measurements of solar protuberances, were noted by the Russian Astronomical Society. He carried out observations at several astronomical observatories; Kharkov, Juriev (now Tartu), Moscow and Pulkovo. After his active participation in the Russian-Swedish expedition to Spitsbergen in 1899-1902 Sykora eventually took up a position at the Tashkent Observatory (now in Republic of Uzbekistan) where he became head astrophysicist in 1906. His main fields of study there were meteors and comets, but he also continued auroral studies, using data from the network of meteorology stations in the Murmansk region. He developed photographic methods and equipment both for auroral, meteor and comet research. In 1911 he took up teaching and taught at several gymnasiums and universities. In 1921 he emigrated to Prague where he became professor of astronomy and did important work to raise the quality of photographic astronomical observations in Czechoslovakia. He died in 1944 (Guth, 1940).

The Russian observers used similar formalized auroral parameters, also in UT: occurrence of aurora, auroral forms (arcs, rayed arcs, bands, single rays, vortices, curls and folds, patches and areas of background luminosity), intensity of aurora in relative units (scale from 5 to 1 , where 1 was the highest intensity), angular velocity of auroral forms, color distribution in auroral forms. The temporal resolution of the observations also varied from several minutes to hours. The angle measurements were based on fixed markers in surrounding mountains and sometimes the positions of stars. Details are described in Chernouss et al. (2005). It is of interest to point out that the weather conditions for observations at Treurenberg Bay and Konstantinovka are strongly different because

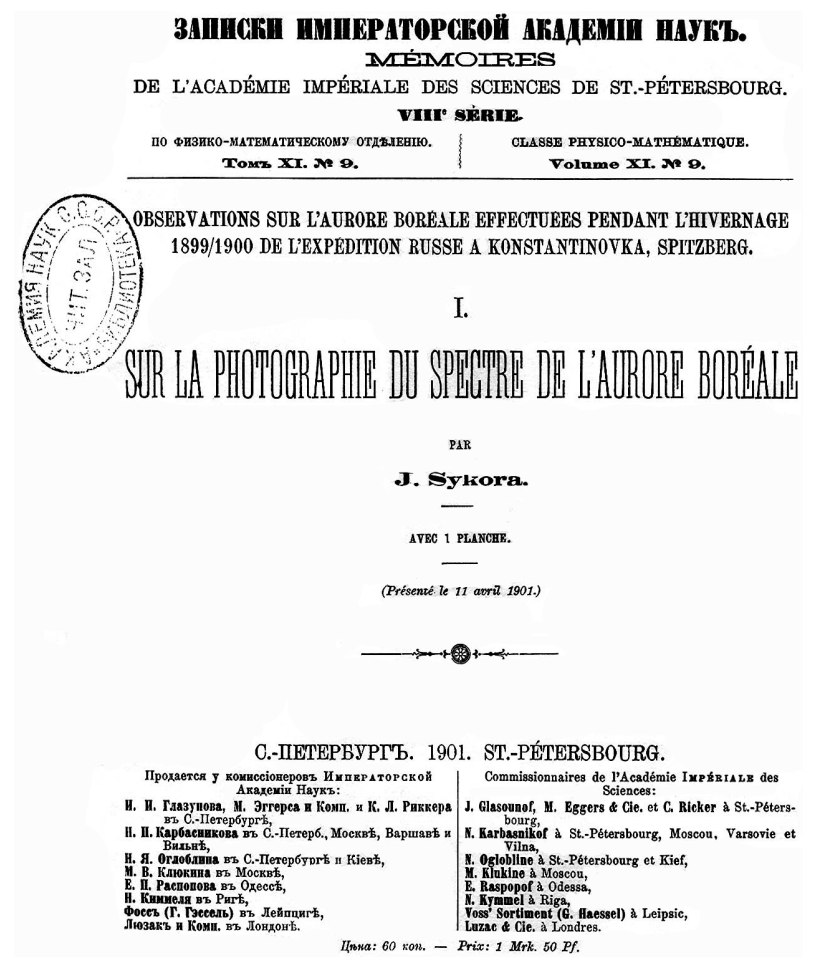

Fig. 5a. Cover page of the report by Sykora (1901a).

of Spitsbergen relief and seaside coast, and simultaneous observations were not so often possible. Another obstacle for comparative analysis is that most observations were not carried out at standardized times (as, for example, exactly on the hour), but were produced mostly during the appearance of aurora, and precisely coincident measurements at the Russian and Swedish stations were rather rare. In most cases of simultaneous observations the accuracy of the Westman team was higher than of the Sykora team. Thus, the measurement errors are mainly defined by the Russian observations. But in any case there are enough events with simultaneous data from the two stations on which some valuable conclusions can be based.

\subsection{Auroral photographs and sketches}

A description of the history of auroral photography, presentation of instruments, and some auroral photos obtained by Sykora in 1899 in Konstantinovka was given in Chernouss et al. (2005). During the same period, photos of aurora were also obtained by Westman. Sykora used a Planar-Zeiss lens with $\mathrm{F}=110 \mathrm{~mm}$ and $\mathrm{D} / \mathrm{F}=1 / 3.6$. The Westman camera was equipped with a Voigtlander and Sohn lens, with $\mathrm{F}=224 \mathrm{~mm}$ and $D / F=1 / 2.5$. These parameters explain why Westman used exposure times from 1 to 4 min while Sykora used exposure times from 3 to $25 \mathrm{~min}$ to photograph aurora. Both scientists used orthochromatic plates to obtain images and 


\section{AURORES BORÉALES}

\section{OBSERVATIONS ET MESURES DE L'AURORE BORÉALE}

FAITES EN 1899 ET EN 1900

A LA BAIE DE

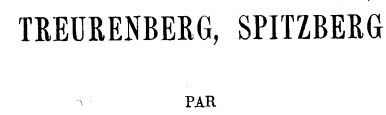

J. WESTMAN.

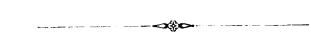

AKTIEBOLAGET CENTRALTRYCKERIET I BTOCKHOLM

1904.

Fig. 5b. Cover page of the report by Westman (1904).

spectra of aurora with high sensitivity. The plates were sensitized in erythrosine solution several days before they were used. Both scientists took acceptable photos of aurora at Spitsbergen, the first ever to be taken from there. Figure 6 shows some photographs of aurora obtained by Westman and some hitherto unpublished photos by Sykora. Westman took a total of seven photos of aurora from 26 December 1899 to 5 January 1900. Sykora took more than 70 photos in the period from October 1899 to February 1900.

It is also necessary to pay attention to the spectral sensitivity of the photographic plates used by Sykora and Westman, because it affects the photographic registration of the auroral spectra. The spectral response of those plates was limited by the green color at the long wavelength end of the spectrum but at the short wavelength end even ultraviolet below $400 \mathrm{~nm}$ could be registered. In ultraviolet the limit is due mostly to the glass of lenses and prisms.

Sketches of aurora drawn by Sykora (Chernouss et al., 2005) give additional information about the position of the aurora, since in these figures relief and mountain features were included as markers of azimuth and elevation angles. They are also very useful to understand the observed morphology of aurora. Westman also drew pictures of the aurora but he mapped auroral forms on standard astronomical star maps. Obviously, it was hard manual work but as a result we have all-sky drawings of the aurora, giving good infor-

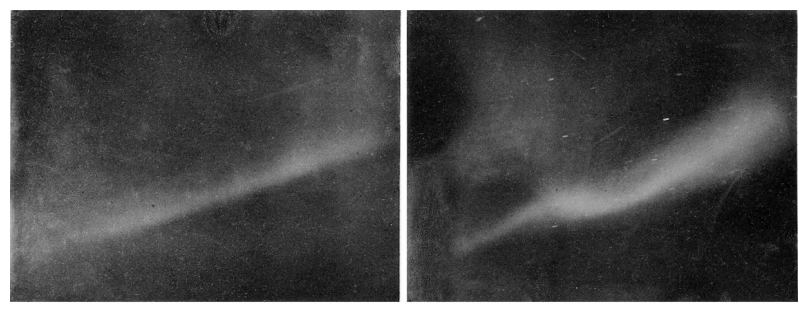

Westman photos

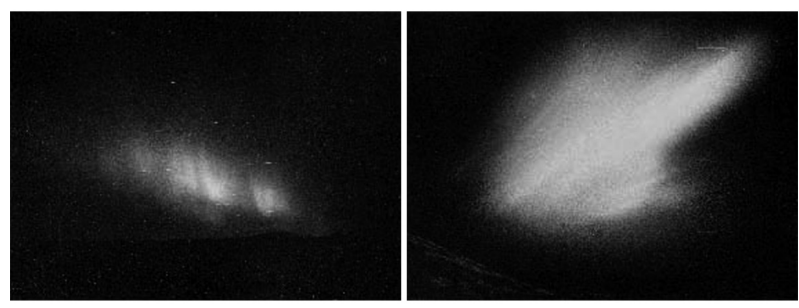

Sykora photos

Fig. 6. Examples of photographs of aurora taken by Sykora and Westman.

mation about their dynamics. These pictures, in combination with visual observations recorded at both stations and the sketches of Sykora, permit us to reconstruct the auroral situation in some cases. An example of an all-sky drawing from Treurenberg Bay is shown in Fig. 7 and a description of the visual observation at Konstantinovka is given in the figure caption. On the basis of such data it is, for example, possible to draw conclusions about the movement of three auroral arcs systems from South to North and about the heights and spatial scales of the aurora.

\subsection{Spectrographs and spectral calibration}

Both Westman and Sykora used the same type of spectrograph (Sykora, 1901a; Westman, 1904) constructed by Toepfer from Potsdam, Germany (Fig. 8). The spectrograph had two prisms, accepting wavelengths from visible into near ultraviolet and a slit width of less than $0.3 \mathrm{~mm}$. Spectral calibration was done periodically and during auroral measurements by a Geissler vacuum tube, whose hydrogen emissions at $486.15,434.07$ and $410.18 \mathrm{~nm}$ and an unidentified emission at $410.18 \mathrm{~nm}$, together with the atmospheric absorption lines at $486.15,430.8$ and $393.8 \mathrm{~nm}$ covered the spectral range of the device. The maximum spectral resolution based on the positions of these spectral lines was estimated to be about $1 \mathrm{~nm}$. Recording of the spectra was done by orthochrome plates that had been sensitized before the measurement. Unfortunately, the spectral sensitivity of the photographic plates used did not permit recording of the red 630.0-nm auroral emission, which is typical of the cleft region. Exposure times of auroral spectra were varied from $4 \mathrm{~h}$ to $28 \mathrm{~h}$ in the observations by Sykora and from 1 to $10 \mathrm{~h}$ 


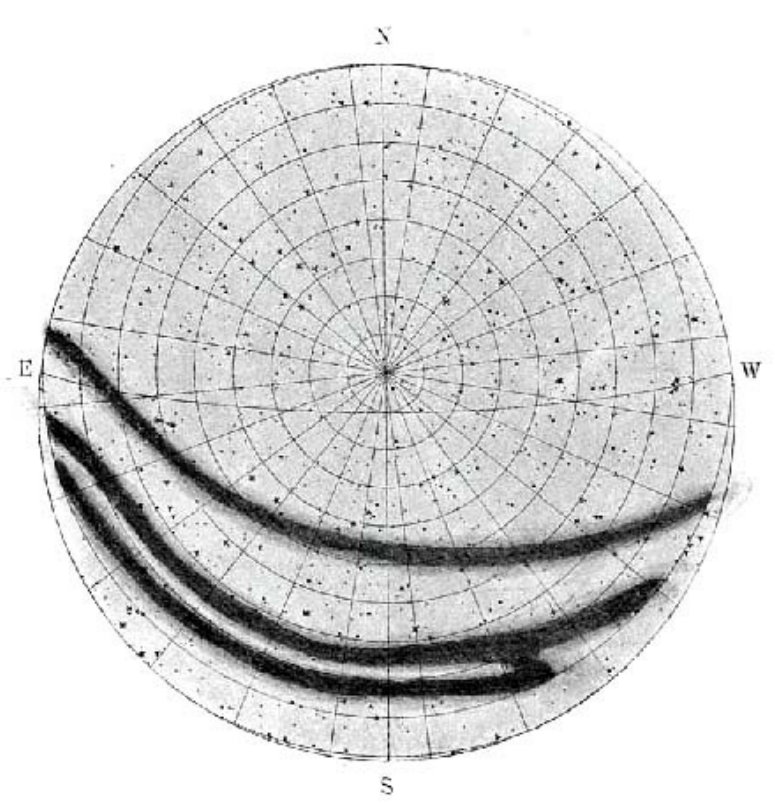

Fig. 7. All-sky drawing by Westman of the aurora as seen from Treurenberg Bay on 27 January 1900 at 16:50 UT. Somewhat earlier the same day, at 16:00 UT, Sykora described the aurora as seen from Konstantinovka: "Three Auroral bands were placed from the Savich Mountain (South-West) to the Chebyshev Mountain (East). The first is near Zenith, the second is to the South not far off Zenith and the third one is between them. Intensity: 3."

in the observations by Westman. The main emissions of aurora were seen directly in the photos, but weak emissions demanded more accurate methods. Westman used a visual microscopy method, which permitted him to see weak emissions on the plate, but did not permit him to prepare well documented evidence of that. Sykora did special processing of primary negatives by preparation of high contrast dianegatives, which gave enhanced spectral images ready for printing (Sykora, 1901a,b; Chernouss et al., 2005).

\section{Data and results}

\subsection{The Auroral Oval from observations at two points}

As is well known Spitsbergen is a unique place where it is possible to observe aurora at all local times, even at midday. The possibility to discover the auroral oval (Korosheva, 1962; Feldstein, 1963; Feldstein and Starkov, 1967) in the 19th century was first pointed out by Alfvén (1967) on the basis of data obtained by Carlheim-Gyllensköld. The occurrence of aurora at Cape Thordsen has a distinct double period from November to January with minima near noon and midnight. During the other months, there is a single maximum and minimum, the former before midnight.

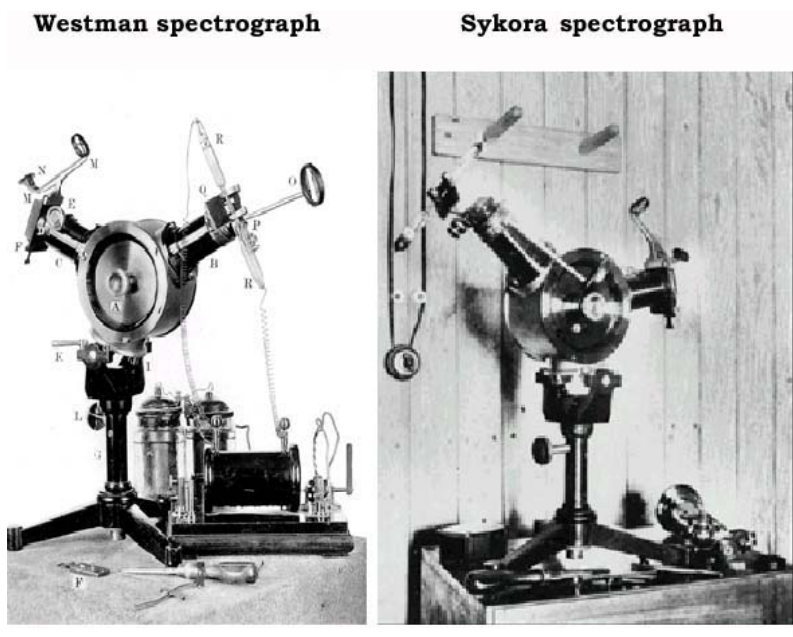

Fig. 8. The spectrographs of Sykora and Westman.



Fig. 9. Azimutal distribution of auroras recorded by Westman (left) and Sykora (right).

The data obtained by Sykora and Westman show not only the existence of the oval but also its continuity. Figure 9 demonstrates the distribution of auroral observations at Konstantinovka and Treurenberg Bay, as a function of the azimuth angle. Figure 10 shows the normalized distribution of the appearance of aurora in three directions, North, Zenith and South, at both stations, as a function of time. All pairs of curves have maxima and minima in about the same time intervals. The temporal shifts between the extrema of the curves from the two stations show that those extrema positions represent the dynamics of the auroral oval. Oval mapping could be done more exactly on the basis of observations from both stations than was achieved from the Konstantinovka observations in the work by Chernouss et al. (2005). The geographical position of Konstantinovka is a little more useful for oval mapping, because of more auroral observations in the North.

\subsection{Some features of the morphology of auroral forms}

Westman and Sykora observed many different types of aurora, both shapes and patterns of temporal development. 

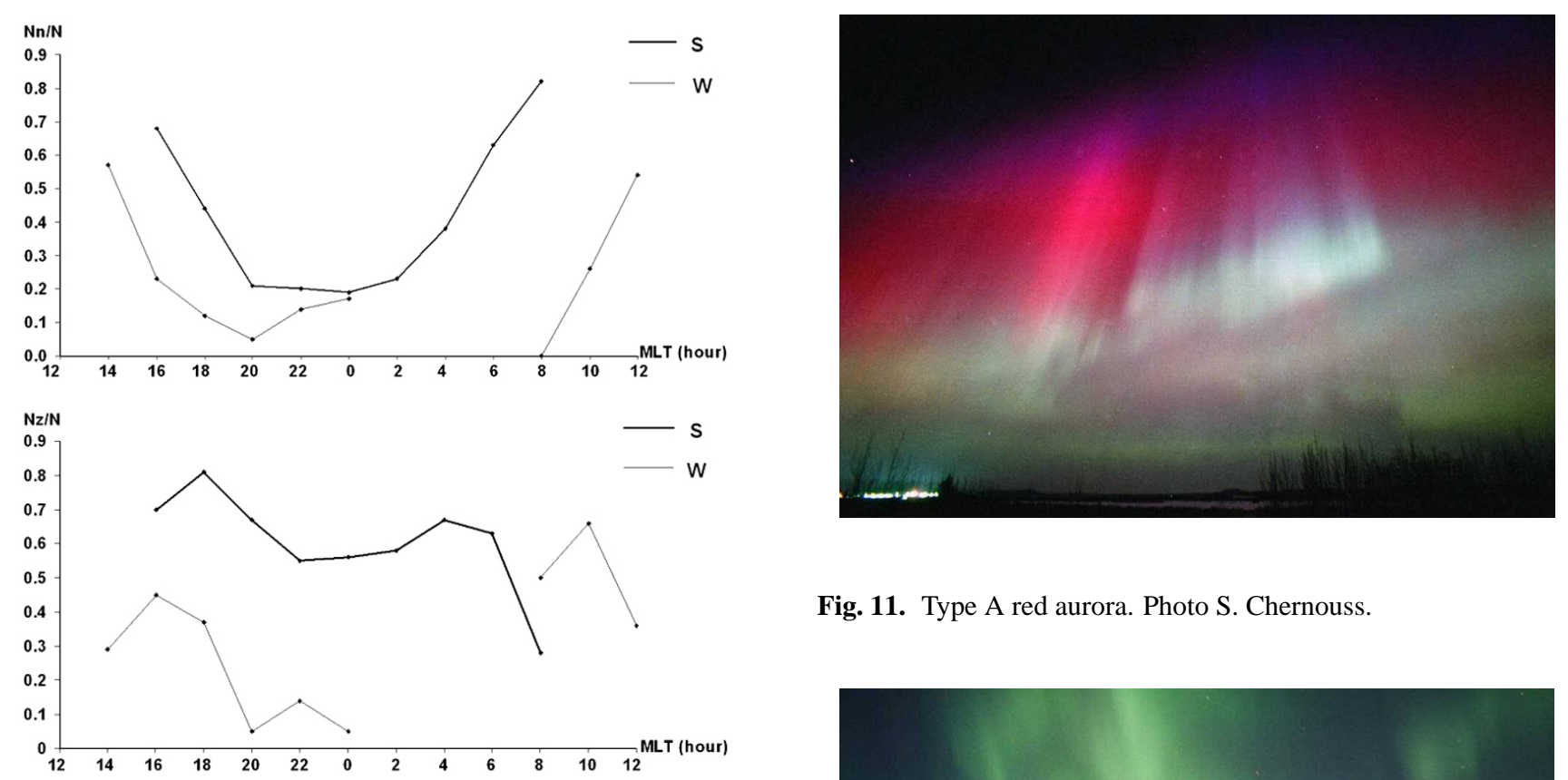

Fig. 11. Type A red aurora. Photo S. Chernouss.
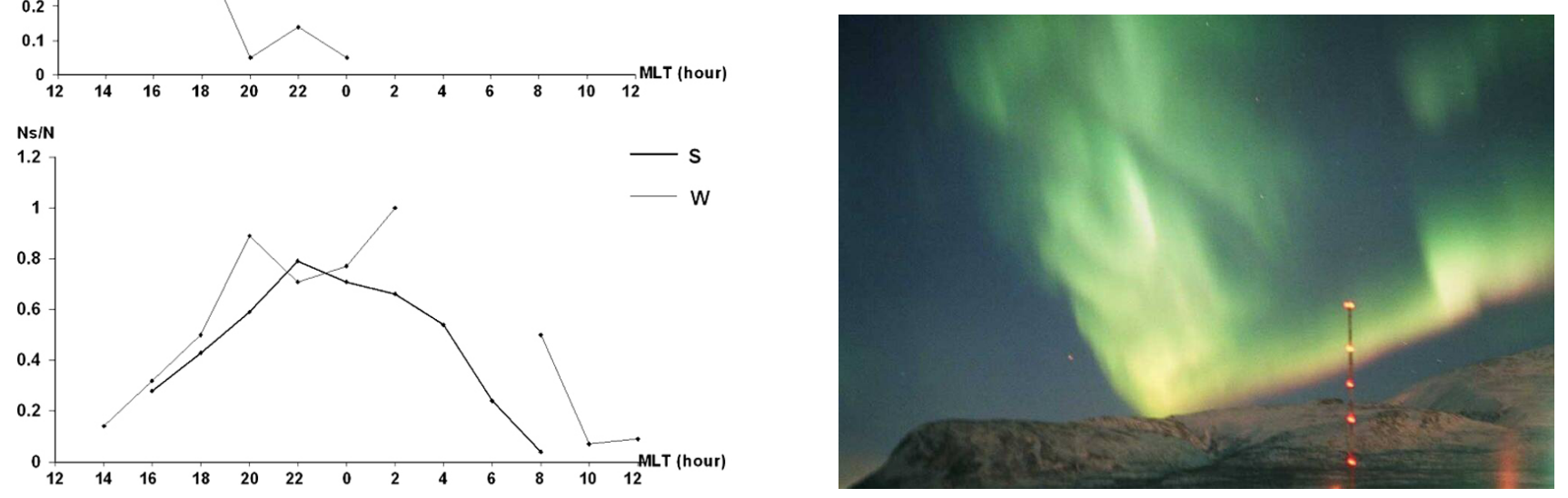

Fig. 10. Normalized occurrence of aurora as a function of magnetic local time. The heavy lines mark observations by Sykora (S) and the thin lines observations by Westman (W). The top panel shows observations north of the stations, the middle panel observations in zenith, and the bottom panel observations to the south.

They both developed classification schemes that differ from what is used today, and they made observations of features that were later overlooked for a long time. We will here discuss some of their morphology observations in light of modern understanding.

The typical cleft aurora, the so-called Type A red aurora (Chamberlain, 1961; Yevlashin, 1968), was observed very rarely by Westman and Sykora. The reason is probably that the winter 1899-1900 took place at a solar activity minimum when such aurora is not so common at Spitsbergen (Chernouss et al., 2005). Figure 11 shows a color photo of a Type A red aurora. The main features of this kind of aurora are long red rays and a maximum red intensity in the upper part of the auroral forms. In the log book Sykora wrote: "A mass of red lights in forms of fire tongues with rose details

Fig. 12. Type B red aurora. Photo P. Chernouss.

streamed from Chebyshev Mountain to Savich Mountain. Intensity is 2 ."

The other type of red aurora, the Type B red aurora (Chamberlain, 1961), was a common event, especially in the evening hours at both stations. This is aurora with a sharp red lower border. Sykora describes an observation in 1899 in the following way: "An arc appears near the horizon. The intensity is 1-2. The arc and flashes inside the arc are red in the rather sharp lower border and green at the high altitude smoothed border." A modern photo is shown in Fig. 12. It is obvious today that this auroral form appears in the Spitsbergen region during the development of substorms that have started at lower latitudes.

A favorite type of aurora for Westman and Sykora was the corona, which was observed in magnetic zenith. Figure 13 is a typical color photo of an auroral corona, together with a table of measurements of magnetic zenith positions made by Westman, who obtained much better agreement between the magnetic zenith positions calculated from 


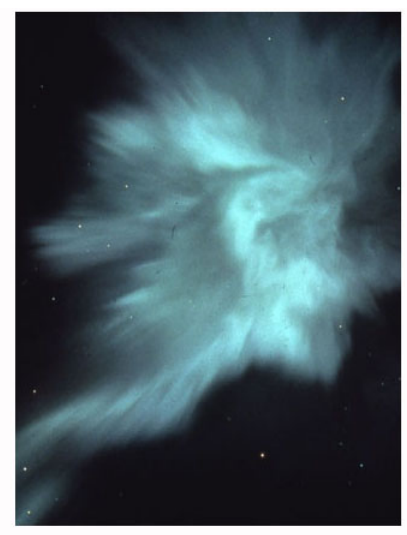

\begin{tabular}{|l|l|l|l|}
\hline Observatory & $\begin{array}{l}\text { Position of } \\
\text { Magnetic zenith } \\
\text { on geomagnetic } \\
\text { measurements }\end{array}$ & $\begin{array}{l}\text { Position of } \\
\text { geomagnetic } \\
\text { zenith on auroral } \\
\text { measurements }\end{array}$ & $\begin{array}{l}\text { Number of } \\
\text { cases }\end{array}$ \\
\hline & Azimuth Inclination & Azimuth Inclination & \\
\hline $\begin{array}{l}\text { Bay of } \\
\text { Treurenberg }\end{array}$ & $169.45 \quad 81.33$ & $170.18 \quad 81.35$ & 36 \\
\hline
\end{tabular}

Fig. 13. Photo of a corona, together with the magnetic zenith positions obtained by Westman from simultaneous optical and magnetic measurements. Photo T. Lövgren.

auroral observations and the geomagnetic measurements than was achieved in the measurements at Cape Thordsen by Carlheim-Gyllensköld (1886).

A sequence of drawings by Westman from 28 January 1900 shows the development of a typical auroral substorm (Akasofu, 1968) in the northern part of the oval. One can see a northward moving auroral arc, then the auroral bulge and surge are shown in the all-sky drawings, as well as the auroral break-up. Sykora pointed out the sequence of events after a bright discrete aurora at the southern border of the oval, when discrete aurora was replaced by diffuse aurora. All these features are understood now as typical phases of the auroral substorm.

The development of a trans-polar arc (Sandholt et al., 2002) was observed by Sykora. Figure 14 presents his sketch of this type of aurora, together with a picture of theta aurora obtained by the Dynamics Explorer satellite.

A type of aurora that Sykora described as rare can be identified with what we today call Black aurora (Nadubovich and Starkov, 1962; Kornilova et al., 1982). Sykora writes in the observation log: "Smooth arc is in the South, its intensity is 3. It is possible to see black structures inside the arc but the nature of those structures is not clear. Detailed observations show that cloudiness can not be a reason for black regions. Similar events have been observed before too". Black aurora, as seen in a TV data frame, is presented in Fig. 15.


Fig. 14. Theta aurora from the Dynamic Explorer satellite imager and a sketch of a similar aurora by Sykora.

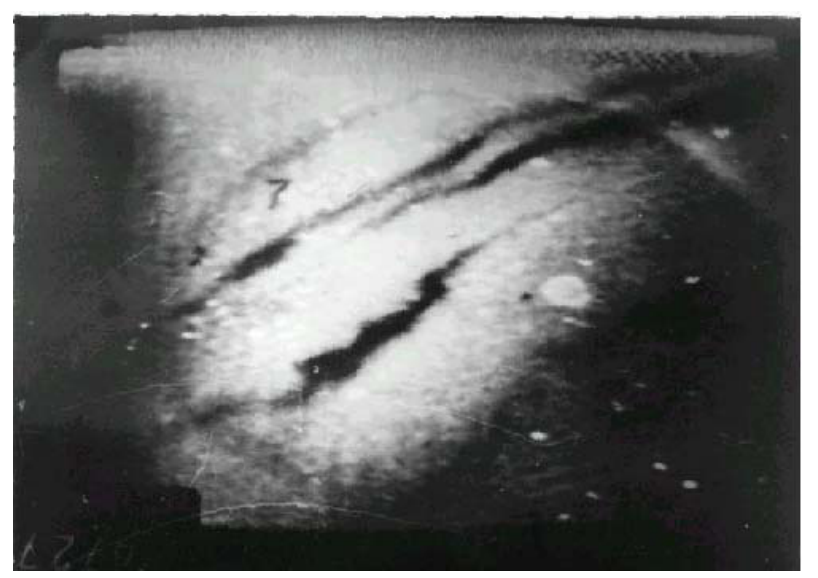

Fig. 15. Black aurora from low light level TV recordings. 
We have just presented here a few selected features of auroral morphology, which are seen in the data of the RussianSwedish expedition. But in the material it is possible to find almost all attributes and signatures of auroral morphology such as curls, vortices, folds, waves, pulsating patches and others, as well as measurements of dynamics and velocities of auroral forms. We have not included the velocity measurements in our discussion here since the more complete data from Westman were presented in terms of angular velocities, which then require knowledge of auroral heights to obtain real velocities.

\subsection{Auroral heights}

Auroral altitude measurements have been discussed since the eighteenth century, when Halley and de Mairan described the triangulation technique (Eather, 1980). Plenty of triangulation measurements were carried out before Størmer did the first precise photographic measurements in 1911 (Størmer, 1955; Brekke and Egeland, 1979). Auroral heights obtained in those early measurements ranged from 15 to $1500 \mathrm{~km}$, most of them far from results of both Størmer and modern studies which give lower borders of about $100 \mathrm{~km}$ for nightside auroras. Even the Encyclopaedia Britannica of 1911 (Encyclopaedia Britannica, 1911) published height measurements, completely different from real altitude values. According to Britannica, attempts to measure auroral heights from Bossekop by the French expedition of 1838-1839 and the Norwegian expedition of 1882-1883 and later from Cape Thordsen by the Swedes had not been very successful. It stated that the most consistent results were those obtained from Godthaab by Paulsen, with the height of the lower border ranging from 6 to $68 \mathrm{~km}$ with an average of $20 \mathrm{~km}$. Similar heights were obtained in 1885 from Cape Farewell by Garde and Eherlin. On one occasion they observed an arc for over half an hour, whose height, according to their measurements, varied between 1.6 and $12.9 \mathrm{~km}$.

An exception was the work of the great English scientist Cavendish, who estimated the auroral heights to be in the range $90-120 \mathrm{~km}$. But this was done just for the single auroral event of 23 February 1784 (Cavendish, 1790).

One big difficulty in triangulation measurements was connected with the length of the baseline, which must be of the order of the height of the aurora. If a very long baseline is used, it becomes increasingly open to doubt whether the same light emitting volume is observed from both ends. If the baseline is short, definite results can hardly be hoped for unless the height is very moderate. The measured baseline between the Russian and Swedish observation points was about $330 \mathrm{~km}$, the ends being on the same meridian, giving a very good geometry for height determination. For this reason we have attempted to analyze the Westman and Sykora data by the triangulation method to see if they could be used for accurate determination of auroral heights. More than one thousand of their measurements from October 1899 to March



Fig. 16. Sketch of aurora on 29 November 1899 drawn by Sykora. Description of the event as viewed from Konstantinovka: "17:48 UT. An auroral band is situated from Chebyshev Mountain (East) through Zenith to West. Intensity: 3. Multiple arcs are near the horizon to the South. Intensity: 4. Diffuse aurora to the South." Description of the same event as viewed from Treurenberg Bay: "17:45 UT. Form: a (arc), Structure: d (diffuse), Position (azimuth and elevation angles of two ends): a1 - 88, h1 - 0; a $2-\mathrm{S}, \mathrm{h} 2-18$, Intensity: 2."

1900 went into the analysis. Of these about one-fourth were coincident in time because of different weather conditions. It was then necessary to find cases where it was reasonably certain that the same auroral form was observed from both stations. Some difficulties were encountered during this work. The first is connected to the method of observation. The Swedish observers used theodolite measurements, but the Russians used visual observations, comparing the positions of the aurora with selected landscape markers, such as mountain features and stars in the sky. So it was necessary to select simultaneous auroral events with rather well defined shapes, because of the limited accuracy of the Russian observations. Another problem was the case of multiple arcs since there is no guarantee that the Swedes and the Russians considered the same arc. This problem is particularly severe for aurora south of Konstantinovka. After careful examination of all events we decided to take into account only auroral events where isolated discrete auroral forms were in zenith of Konstantinovka and were observed within the same $10-15 \mathrm{~min}$ time span from Treurenberg. Cases with considerable movements of auroral forms along the meridian were also deleted. A sketch by Sykora of a typical event included in the study, 29 November 1899, is presented in Fig. 16.

Among the most unambiguous events is the aurora of 1 December 1899 at 09:35 UT, of which we have a photo and description from Konstantinovka and a description of the aurora in Treurenberg Bay, and the aurora of 28 January 1900 at 05:42 UT (Fig. 17), where we have an all-sky drawing of an aurora at Treurenberg Bay and descriptions of the aurora at both stations. We also took into account the aurora of 28 January 1900 at 08:06 UT, although the aurora was not in zenith at Konstantinovka (Fig. 18), but we have an all-sky drawing of the aurora at Treurenberg Bay, a sketch of the aurora at Konstantinovka and descriptions at both stations. After 


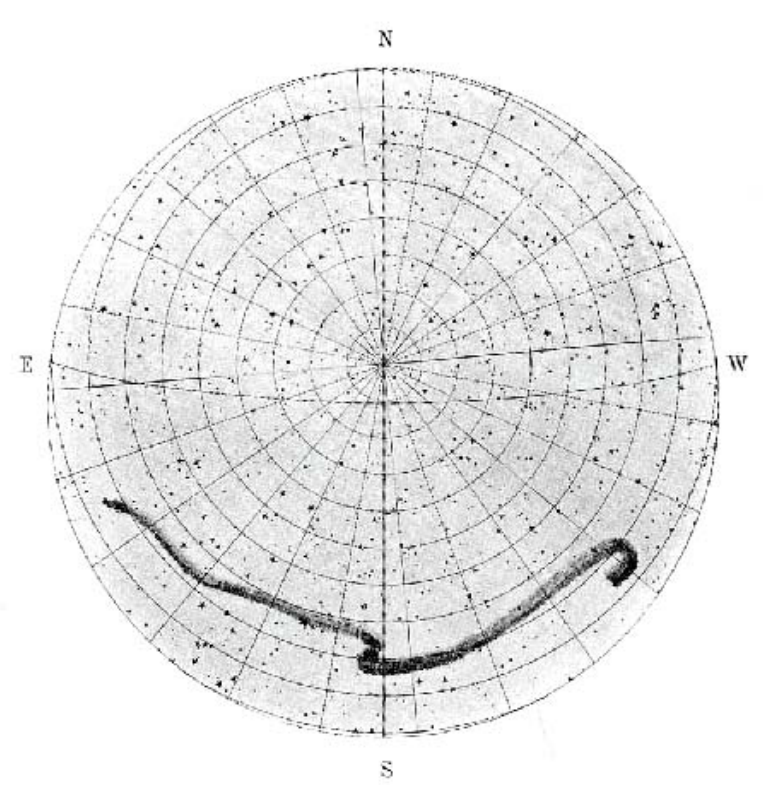

Fig. 17. All-sky drawing of aurora at Treurenberg Bay on 28 January 1900 at 17:42 UT. At the same time the aurora at Konstantinovka was described in the following way: "17:42 UT. An auroral band like a snake was situated from East to West. Circulation of luminosity inside the band is varied from West to East to East to West. Intensity: 2.”

all operations only 24 events were selected. The distribution of heights of the lower borders of those events is presented in Fig. 19. The height of most events was between 80 and $120 \mathrm{~km}$. The heights were derived by simple trigonometry, assuming a plane Earth. If we take into account the Earth curvature, about $10 \mathrm{~km}$ must be added, giving heights of 90$130 \mathrm{~km}$, in good agreement with 20th century data.

\subsection{Auroral spectra}

Since the Russian-Swedish Expedition of 1899-1900 was unusually well provided with spectrographic measurement equipment, the results of the spectral observations of aurora were on a discovery level. The main auroral emissions at $391.4 \mathrm{~nm}, 427.8 \mathrm{~nm}, 470.9 \mathrm{~nm}$ and 557.7 are clearly seen in the photographic plates presented in the Sykora $(1901 \mathrm{a}, \mathrm{b})$ and Westman (1904) reports. But in addition some weak auroral emissions were revealed, not only for the first time in Spitsbergen, but for the first time ever. A detailed analysis of the spectral observations by Sykora was done by Chernouss et al. (2005). Therefore, we shall concentrate on the measurements by Westman and compare Westman and Sykora spectral data.

Figure 20 presents primary data of observed auroral spectra obtained by Sykora and Westman, together with a synthetic spectrum of aurora presented in the review of the Swedish IPY expedition in 1882-1883 (Carlheim-
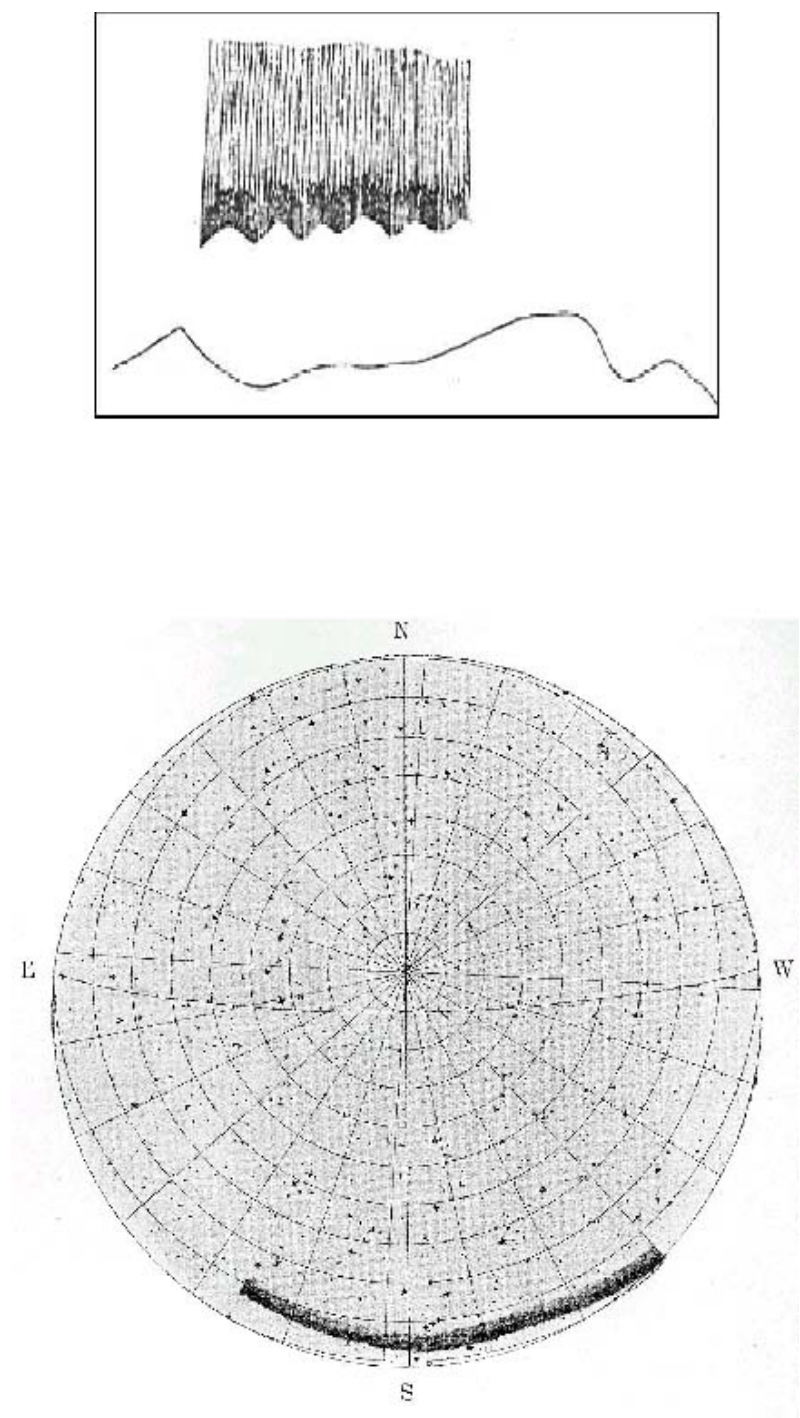

Fig. 18. All-sky drawing of aurora at Treurenberg Bay and sketch of aurora at Konstantinovka on 28 January 1900 at 08:06 UT.

Gyllensköld, 1886). The 1882-1883 spectrum was obtained by the visual spectroscopy method developed by the Uppsala school that was headed by the famous physicist Anders Ångström, the discoverer of the main emissions of the auroral spectrum (Ångström, 1869, 1874). From the first glance the spectrum obtained by visual spectroscopy is richer than the spectrum photos of Sykora and Westman, but visual spectroscopy fails to detect the ultraviolet emissions because the human eye is not sensitive in this spectral region. On the other hand, the photographic plates used by Sykora and Westman could not register auroral emissions in the yellow-red region of the spectrum. In the primary data of Sykora we can see, besides four bright main emissions, about ten weak emissions with wavelengths in the ultraviolet, violet and blue regions of the spectrum. These emissions 


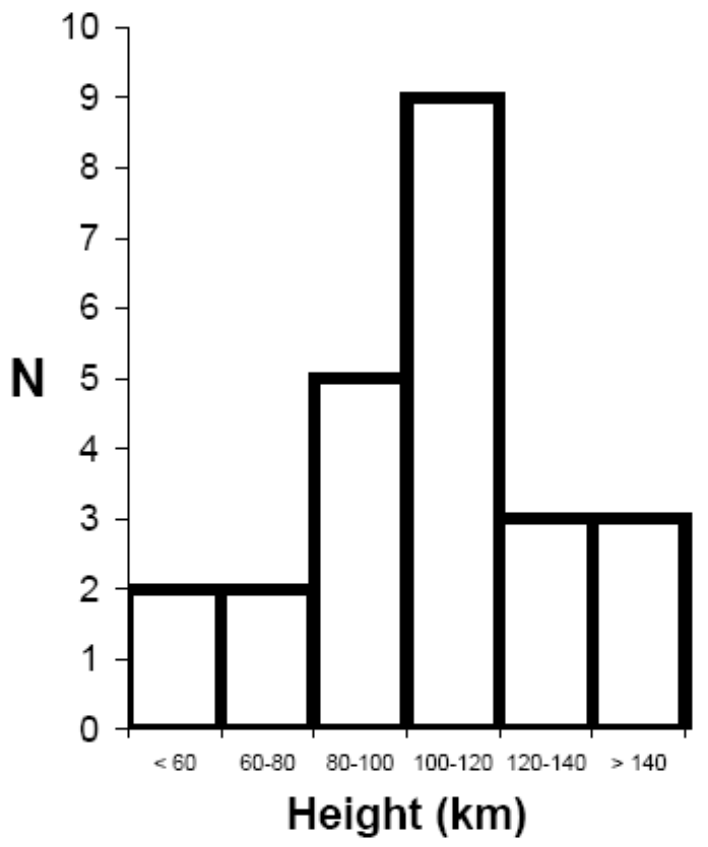

Fig. 19. Distribution of auroral heights for the 24 events selected. The corresponding elevations as measured from Treurenberg Bay ranged between 10 and 30 degrees.

are well documented in the synthetic spectrum of aurora by Sykora (1901a,b) and recent reanalysis of Sykoras spectral photographs in Chernouss et al. (2005).

The results of Westman's spectral analysis of his exposed plates are more impressive. He revealed about 30 weak auroral emissions at wavelengths between 520.5 and $351.3 \mathrm{~nm}$ by analyzing his photographic plates under a microscope. Ten of these emissions were in the ultraviolet range, below $397 \mathrm{~nm}$, where prior to this expedition only two emissions had been reported in aurora (Chernouss et al., 2005). The additional ones were thus new discoveries. Unfortunately, Westman did not have the possibility to photograph the microscope output, but all obtained spectral lines were presented in digital tables. Thus, the difference between the data presentations of Sykora and Westman is that Sykora presented well documented photos of spectra while Westman presented results obtained by analysis of his photos under a microscope. The reason for this is the exposure times during the measurements. Westman took six photos of auroral spectra in January-February 1900 with exposure times of $1 \mathrm{~h} ; 2 \mathrm{~h} 50 \mathrm{~min} ; 5 \mathrm{~h} 35 \mathrm{~min} ; 4 \mathrm{~h}$ $5 \mathrm{~min} ; 2 \mathrm{~h} 20 \mathrm{~min} ; 10 \mathrm{~h} 6 \mathrm{~min}$ and Sykora took five photos of spectra in October-December 1899 with exposure times of $4 \mathrm{~h} 49 \mathrm{~min} ; 4 \mathrm{~h} ; 24 \mathrm{~h}, 11 \mathrm{~h} ; 28 \mathrm{~h} 7 \mathrm{~min}$. The longer exposure times in Sykora's measurements permitted him to prepare negatives of higher quality, giving printed positives used in the further analysis by other authors. The weak spectral lines and bands of aurora, obtained from the measurements of Sykora and Westman, are listed in Table 1, together with
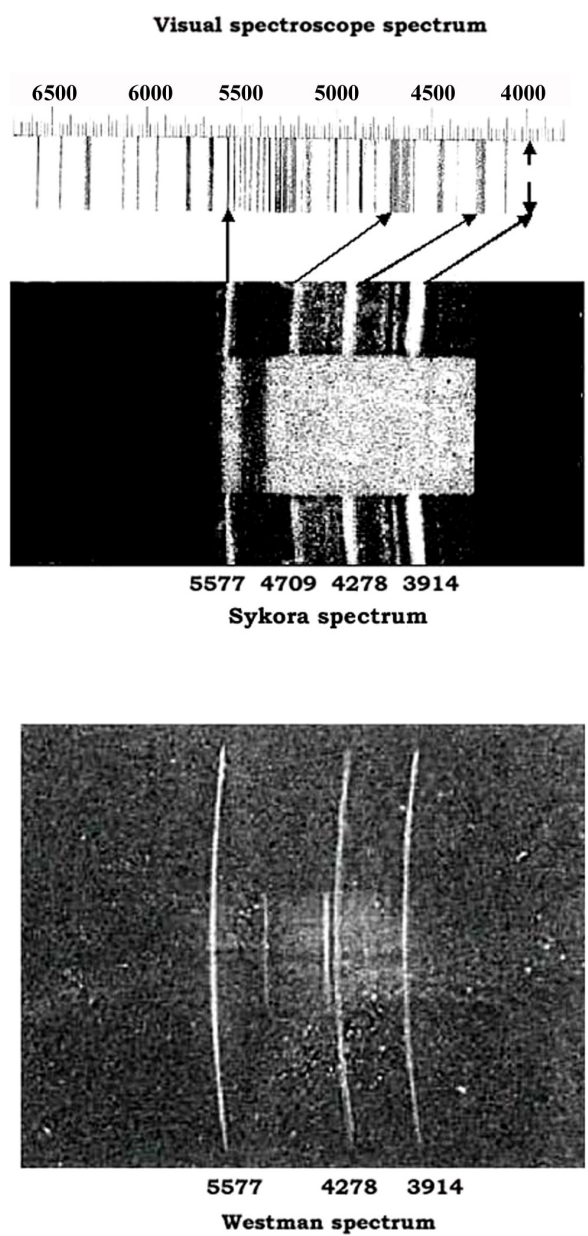

Fig. 20. Auroral spectra obtained by Sykora and Westman, together with calibration spectra and an auroral spectrum constructed earlier from visual spectroscope observations (Carlheim-Gyllensköld, 1886).

20th century data (Chamberlain, 1961). The criterion used to identify an emission detected by Westman or Sykora as an emission listed by Chamberlain is that the wavelength difference is smaller than $1 \mathrm{~nm}$, which was the approximate resolution of the Westman and Sykora data. If Chamberlain lists more than one emission within this interval, the Chamberlain emission closest in wavelength is listed. It is clearly seen that almost all emissions of aurora found in 1899-1900 agree well with modern results. Emissions not matching modern data are pointed out by question marks. Sykora and Westman had the same opinion on the physical nature of most of the emissions. They were quite sure that the luminosity of aurora is similar to the luminosity of gases in a vacuum tube. Sykora identified some of the emissions in positive and negative discharges in a vacuum tube and pointed out the important role of the molecules $\mathrm{N}_{2}$ and $\mathrm{N}_{2}^{+}$in aurora (Sykora, 
Table 1. Wavelengths of weak auroral spectral lines measured by Westman and Sykora, together with an interpretation of these lines based on data in Chamberlain (1961). For line 17 there are three lines meeting the identification criterion.

\begin{tabular}{|c|c|c|c|c|c|c|}
\hline & Westman 1900 & & Sykora 1899 & Chamberlain 1961 & & \\
\hline No & wavelength (nm) & I (units) & wavelength (nm) & wavelength (nm) & Atom or molecule & Multiplet or band \\
\hline 1 & 358.9 & 5 & & 358.2 & $\mathrm{~N}_{2}^{+}$ & $1 \mathrm{NG}(1.0)$ \\
\hline 2 & 360.7 & 5 & & 360.2 & $\mathrm{~N}_{2}^{2}$ & $\mathrm{VK}(0.10)$ \\
\hline 3 & 370.3 & 5 & 370.7 & 371.0 & $\mathrm{~N}_{2}$ & $2 \mathrm{PG}(2.4)$ \\
\hline 4 & & & 375.4 & 375.5 & $\mathrm{~N}_{2}$ & $2 \mathrm{PG}(1.3)$ \\
\hline 5 & $379.2 ?$ & 6 & & $?$ & $?$ & $?$ \\
\hline 6 & 380.3 & 7 & 380.4 & 380.5 & $\mathrm{~N}_{2}$ & $2 \mathrm{PG}(0.2)$ \\
\hline 7 & 386.1 & 10 & & 385.8 & $\mathrm{~N}_{2}^{+}$ & $1 \mathrm{NG}(2.2)$ \\
\hline 8 & 387.6 & 5 & & 387.5 & OII & 13 \\
\hline 9 & 388.0 & 10 & & 388.2 & OII & 11 \\
\hline 10 & 393.6 & 8 & & 394.3 & $\mathrm{~N}_{2}$ & $2 \mathrm{PG}(2.5)$ \\
\hline 11 & 394.7 & 7 & & 394.7 & OI & 3 \\
\hline 12 & 398.6 & 6 & & 398.3 & OII & 6 \\
\hline 13 & 399.6 & 10 & 399.5 & 399.8 & $\mathrm{~N}_{2}$ & 2PG(1.4) \\
\hline 14 & 406.7 & 5 & 405.7 & 405.9 & $\mathrm{~N}_{2}$ & $2 \mathrm{PG}(0.3)$ \\
\hline 15 & 407.8 & 6 & 408.3 & 407.9 & OII & 10 \\
\hline 16 & 422.5 & 8 & 419.0 & 419.9 & $\mathrm{~N}_{2}^{+}$ & $1 \mathrm{NG}(2.3)$ \\
\hline 17 & 423.0 & 6 & & 422.3 & NI & 5 \\
\hline 17 & 423.0 & 6 & & 423.7 & $\mathrm{~N}_{2}^{+}$ & $1 \mathrm{NG}(1.2)$ \\
\hline 17 & 423.0 & 6 & & 423.7 & NII & 48 \\
\hline 18 & 424.1 & 7 & & 424.2 & NII & 47 \\
\hline 19 & 432.9 & 6 & & 432.0 & $\mathrm{~N}_{2}$ & $\mathrm{VK}(1,13)$ \\
\hline 20 & 433.6 & 6 & & 433.7 & OII & 2 \\
\hline 21 & 434.3 & 5 & & 434.4 & $\mathrm{~N}_{2}$ & $2 \mathrm{PG}(0.4)$ \\
\hline 22 & 435.6 & 5 & 435.4 & 435.1 & OII & 16 \\
\hline 23 & 437.0 & 8 & & 436.9 & OII & 26 \\
\hline 24 & 442.0 & 9 & 442.9 & 442.5 & $\mathrm{~N}_{2}$ & $\mathrm{VK}(2.14)$ \\
\hline 25 & 448.9 & 5 & & 448.8 & NII & 21 \\
\hline 26 & 455.0 & 5 & & 455.4 & $\mathrm{~N}_{2}^{+}$ & $1 \mathrm{NG}(3.5)$ \\
\hline 27 & 455.9 & 6 & & 456.5 & NII & 14 \\
\hline 28 & 466.8 & 8 & & 466.2 & OII & 1 \\
\hline 29 & $469.8 ?$ & 6 & & $?$ & $?$ & $?$ \\
\hline 30 & 470.8 & 10 & 471.0 & 470.9 & $\mathrm{~N}_{2}^{+}$ & $1 \mathrm{NG}(0.2)$ \\
\hline 31 & 483.0 & 6 & & 483.7 & $\mathrm{~N}_{2}$ & $\mathrm{VK}(2.15)$ \\
\hline
\end{tabular}

1901a,b; Chernouss et al., 2005). He proposed to study nitrogen spectra in a vacuum tube without any electrodes and vary the gas temperature and density to establish their influence on the spectrum and spectral line positions. He erroneously proposed the brightest green line at $557.7 \mathrm{~nm}$ to be a krypton line measured by him in laboratory experiments. The oxygen origin of that line was not established until 1923, when better vacuum equipment had become available (Eather, 1980). Westman identified 82 nitrogen lines at the negative pole in vacuum discharges (Westman, 1904; Encyclopaedia Britannica, 1911). The interval considered by Westman contains at least 300 oxygen and nitrogen lines. Amongst the lines thus identified are the two principal auroral lines having wavelengths $427.64 \mathrm{~nm}$ and $391.35 \mathrm{~nm}$.

\section{Discussion and conclusions}

Our analysis of the auroral observation data obtained by the bilateral Swedish-Russian expedition at Spitsbergen shows that it was until then the best prepared and organized observation campaign of aurora by different methods at two points along the same geographical meridian in the Arctic. The materials and data of both teams could have made it possible to discover the auroral oval in the 19th century. The data allow for auroral height determination by the triangulation method from two points and can, once the height has been established, then be used to give correct estimates of the horizontal scales of different auroral forms and their velocities. Auroral morphology data give descriptions of a large fraction of the auroral phenomena we know about today. Observations 




Fig. 21. The auroral oval and the position of Spitsbergen at different times of the day during a year of solar activity minimum.

of auroral spectra were done with the maximum accuracy possible at that time, and permitted Sykora and Westman to discover a couple of new emissions in the near ultraviolet. Both Sykora and Westman obtained the first acceptable photos of aurora, perhaps not only at Spitsbergen but in all of the Arctic. It should be remembered that Spitsbergen is an unusual place where measurements unaffected by daylight can be made around the clock during the midwinter period, making it possible to follow the dynamics of different magnetospheric domains and different kinds of particle precipitation by optical methods. Moreover, Spitsbergen may be the best place for high-latitude auroral study, because an observer there can study the auroral oval at all local times (see Fig. 21). Unfortunately, Sykora and Westman never met and discussed their results together after the expedition and our task was to show the validity and significance of their results from a modern point of view. In our opinion Josef Sykora and Johan Westman were great auroral scientists who looked forward in many directions of auroral physics.

Acknowledgements. The authors thank: The St. Petersburg department of the Archive of the Russian Academy of Sciences for search of the expedition data, St. Petersburg Library of RAS for help in copying of old sources, Nyköping city archives and Centre for History of Science, Royal Swedish Academy of Sciences for photos from Treurenberg Bay and of Westman, P. Kotrc for information regarding the biography of Sykora, L. Yevlashin and G. Starkov for useful discussion, O. Antonenko for help in preparation of the paper. We are grateful to R. Eather, S.-I. Akasofu, A. Brekke and A. Egeland, whose monographs were used as guide books in our study. This research was partly supported by the Nordic Council of Ministers through grant 087043-60105, Network for Groundbased Optical Auroral Research in the Arctic Region, and by the Norwegian Research Council via the Norwegian and Russian Upper Atmospheric Co-operation On Svalbard (NORUSCA).
Topical Editor U.-P. Hoppe thanks H. C. Carlson and another anonymous referee for their help in evaluating this paper.

\section{References}

Akasofu, S.-I.: Polar and Magnetospheric Substorms, D. Reidel Publ., Dordrecht, Holland, 1968.

Alfvén, H.: Note on the "auroral oval”, J. Geophys. Res., 72, 3503, 1967.

Ångström, A. J.: Spektrum des Nordlichts, Pogg. Ann., 137, 161$163,1869$.

Ångström, A. J.: Du spectre de l'aurore boréale, J. Phys. Theor. Appl., 3, 210-214, 1874.

Brekke, A. and Egeland, A.: Nordlyset, Grøndal og Søn Forlag AS., Oslo, 1979.

Carlheim-Gyllensköld, V.: Exploration Internationale des Regions Polaires, 1882 to 1883 , Norstedt, Stockholm, 1886.

Carlheim-Gyllensköld, V.: Uppmätning av en meridiangradbåge på Spetsbergen genom en svensk-rysk expedition (in Swedish), Ymer, 20, 209-227, 1900.

Cavendish, H.: On the height of the luminous arch which was seen on February 23, 1734, Phil. Trans. Roy. Soc., 80, 101-105, 1790.

Chamberlain, J. W.: Physics of the Aurora and Airglow, Academic Press, New York and London, 1961.

Chernouss, S. A., Starkov, G. V., and Yevlashin, L. S.: World first complex optical instrumental observations of aurora in the Arctic 1899-1900, Ann. Geophys., 23, 1523-1531, 2005, http://www.ann-geophys.net/23/1523/2005/.

Deehr, C. S. and Egeland, A.: Auroral morphology, Ann. Geophys., 28, 415-425, 1972, http://www.ann-geophys.net/28/415/1972/.

Eather, R. H.: Majestic Lights. The Aurora in Science, History, and the Arts, AGU, Washington, D.C., 1980.

Encyclopaedia Britannica: V02, 934, 1911

Feldstein, Y. I.: Some aspects of the auroral morphology and geomagnetic disturbances in the high latitudes (in Russian), Geomagn. Aeronomy, 3, 227-239, 1963.

Feldstein, Y. I. and Starkov, G. V.: Dynamics of auroral belt and polar geomagnetic disturbances, Planet. Space Sci., 15, 209-229, 1967.

Guth, V.: Prof. J. Sykora (in Czech), Rise Hvezd, 21(3), 67-68, 1940.

Kornilova, T. A., Chernouss, S. A., and Pudovkin, M. I.: Black aurora, Proceedings of 10th Annual Meeting on Upper Atmospheric Studies by Optical Methods, Grass, France, pp. 198-206, 1982.

Korosheva, O. V.: Daily drift of continuous auroral ring, Geomagnetism and Aeronomy, 2, 839-850, 1962.

Nadubovich, Y. A. and Starkov, G. V.: Filament structure of the weak homogeneous auroral arcs, Geomagn. Aeronomy, 2, 7173, 1962.

Nordisk Familjebok: Uggleupplagan (in Swedish), 32, 71-72, 1921.

Nordlander, J.: Lövvik förr och nu, Blog (in Swedish), http:// jannordlander.spaces.live.com, 2006.

Sandholt, P. E., Carlson, H. C., and Egeland, A.: Dayside and Polar Cap Aurora, Kluver Academic Publishers, Dordrecht/Boston/London, 2002.

Størmer, C.: The Polar Aurora, Clarendon Press, Oxford, 1955. 
Sykora, J.: Sur la Photographie du Spectre de L'Aurore Boreale, Memoires de L'Academie Imperiale des Sciences de St.Petersbourg, 9, 1-9, 1901a.

Sykora, J.: Die Wellenlängen der photographich erhaltenen Linien des Nordlichtsspectrums, Astronomische Nachrichten, 156, 325, $1901 b$.

Sykora, J.: Observations Directes et Photographies des Aurores Boreales, Memoires de L'Academie Imperiale des Sciences de St.Petersbourg, 14, 1-50, 1903.

Westman, J.: Observations et mesures de l'aurore boreale faites en 1899 et en 1900 a la baie de Treurenberg, Spitzberg, Aktiebolaget centraltryckeriet, Stockholm, 1904.
Wråkberg, U.: The Russo-Swedish Arc-of-Meridian expeditions to Spitsbergen 1898-1902, in: International scientific cooperation in the Arctic, edited by: Bouzney, B. E., pp. 15-52, Moscow, Scientific World, 2002.

Yevlashin, L. S.: On the character of auroral glow within the auroral region at periods of solar activity maximum and minimum, Ann. Geophys., 24, 527-530, 1968, http://www.ann-geophys.net/24/527/1968/. 